\title{
Highly Biocompatible Porous NiTi Alloys
}

\author{
Tejal A. Raval ${ }^{1^{*}} \&$ Ishverbhai Patel ${ }^{2}$ \\ ${ }^{1}$ Vidhydeep Institute of Science, Anita, Kim, India \\ ${ }^{2}$ Veer Narmad South Gujarat University, Surat, Gujarat, India \\ E-mail addresses:tejalshah1323@gmail.com
}

Received Feb 2020

Received in revised: Feb 2020

Published: March 2020

\begin{abstract}
Nickel Titanium alloys have proved to be a perfect choice for materials used for medical devices like catheters, pacemakers and stone removal mesh. However, there are some challenges related to the shape and size modifications required to suffice the applications. The alloy needs improvements particularly in the areas of porosity for bone replacement, radiopacity, super elasticity and fatigue strength. There is a wide range of applications of biocompatible Porous NiTi alloys in the areas of inter body fusion devices, synthetic bone grafting, etc. Although it cannot be denied of the possibility of high corrosion factor of Porous NiTi alloys as compared to solid NiTinol due to greater surface area in contact with the body fluids. Such cases include definite surface preparation to cater to the need for increased biocompatibility. This paper includes the synthesis of porous NiTi alloys through the sintering process along with a check of the surface treatments and its effects on the properties related to corrosion of Porous NiTinol. The Alloys were subjected to different treatments like dry heating, boiling in water and passivation. The corrosion resistance, after and before the treatments were evaluated.
\end{abstract}

Keywords: Porous NiTi, biomedical implants, devices, sintering process, NiTinol biocompatibility

C2020 The Authors. Published by Fundamental Journals. This is an open access article under the CC BY-NC https://creativecommons.org/licenses/by-nc/4.0/

https://doi.org/10.14331/ijfps.2020.330135

\section{INTRODUCTION}

NiTi shape memory alloys, known as NiTinol, have gained a lot of importance due to its vast application range in fields like biomedical devices and aerospace industries. The excellent mechanical and shape memory property and the biocompatible property of the alloy cater to the different requirements of the alloy (Abidi, Khalid, Farooq, Hussain, \& Maqbool, 2015). Especially for biomedical implants, the properties such as low modulus comparable to bones, adequate yield strength, higher ductility and elasticity, good corrosion resistance and biocompatibility are essential for long-term performance (Geetha, Singh, Asokamani, \& Gogia, 2009; Huang et al., 2010). Comparing the Ti-based shape memory alloys and other alloys like Co-Cr alloys, NiTinol has proved to be the most suitable material for biomedical implants due to its better biocompatibility and low modulus (Pelton, Dicello, \& Miyazaki, 2000). Recent studies show that Porous NiTinol has enhanced its popularity as a material for implant as it has a unique cellular structure which caters to ingrowth of tissues, medicine transportation, nutritional exchange and low level of stiffness to promote integration with the host bone in the body 
due to $2 \%$ strain recovery (Kapoor, 2017; X. Wang et al., 2016). The porous NiTi alloys can be fabricated by various powder metallurgy techniques (Aihara, Zider, Fanton, \& Duerig, 2019). In this study, the porous NiTi is fabricated by melting $\mathrm{NaCl}$ spacer powder through conventional sintering process. Porous NiTi alloys are utilized widely in a variety of medical applications like bone grafting, bone reconstruction, intervertebral fusion devices, stents, tissue repair, and dental implants. The properties like osteoconductivity, open porosity, superelasticity, and high strength caters to the wide application areas of Porous NiTi alloys. Corrosion of such material leads to device failure as well as hazardous effects in patients like allergies, toxins in blood and carcinogenic effects. (Aihara et al., 2019) Nitinol normally has a 1:1 ratio but the shape memory effect occurs between 49.5 at $\%$ to 53 at $\%$ Ni. To understand the effects of local treatment on the corrosion resistance of porous NiTi alloys, four different methods of surface treatment were used. The treatments include boiling in distilled water at $132^{\circ \mathrm{C}}$ for $30 \mathrm{~min}$, dry heating in $1 \mathrm{~atm}$ at $132^{\circ \mathrm{C}}$ for 1 hour, etching in the acid mixture for $1 \mathrm{~min}$ and passivation in $20 \%$ concentrated Nitric acid for $20 \mathrm{~min}$. The corrosion susceptibility of surface-treated Porous NiTinol was evaluated by conducting cyclic polarization tests preferably using ASTM F 2129-08 (O’Brien, Carroll, \& Kelly, 2002; Thierry, Tabrizian, Trepanier, Savadogo, \& Yahia, 2000).This is preferably the currently in vitro method for assessing the corrosion resistance of biologically implantable medical devices, where the difference between the breakdown potential, Eb, and rest potential, Er, is used as a measure of the resistance to corrosion. Samples were subjected to each of the surface treatments and the average values of $\mathrm{Eb}$ and Er were calculated (J. Wang et al., 2015).

\section{EXPERIMENTATION}

1) Fabrication: Powdered Sodium chloride $(60 \%$ spherical morphology) was used as the spacer during the sintering process as foams with spherical morphology has improved mechanical properties. Two types of $\mathrm{NaCl}$ powder with the mean particle size of $230 \mu \mathrm{m}$ and $425 \mu \mathrm{m}$ were used to synthesize samples with codes as Ni200 and Ni400, respectively. $50.5 \mathrm{at} \% \mathrm{Ni}$ and $49.5 \% \mathrm{Ti}$ were mixed in a ball mill at 200rpm for 3 hours. The $\mathrm{NaCl}$ powder was blended with the premixed $\mathrm{Ni}$-Ti powder in a rotating cylinder for another 12 hours. The powders were then compacted by the uniaxial press at $300 \mathrm{MPa}$. The samples were then sintered under a high vacuum $\left(\leq 10^{-3}\right.$ bar $)$ at $1000^{\circ} \mathrm{C}$ for 4 hours. Desalination was done for 12 hours, with the circulation of distilled water to ensure complete removal of $\mathrm{NaCl}$ from the foam samples. $\mathrm{XRD}$ was used to investigate the phase of the samples. Phase difference was studied using the etching by Kroll's reagent $\left(10 \mathrm{HNO}_{3}-2 \mathrm{HF}-88 \mathrm{H}_{2} \mathrm{O}\right)$.

2) The Ni200 samples were taken into consideration for further study. Several plates were cut with a high speed saw for obtaining the samples for further research. The local treatments which were done on the five samples of Ni200 are as follows:

a) The samples were etched in an acid mixture of $1 \mathrm{HF}+$ $4 \mathrm{HNO}_{3}+5 \mathrm{H}_{2} \mathrm{O}$ at room temperature with continuous ultrasonic stirring for $1 \mathrm{~min}$.

b) The samples were boiled in distilled water at $132^{\circ \mathrm{C}}$ for 30 min. and then passivated by immersing them in $20 \%$ conc. $\mathrm{HNO}_{3}$ at $80^{\circ \mathrm{C}}$ for $20 \mathrm{~min}$. c) The untreated samples were dry heated at $132^{\circ \mathrm{C}}$ in an open furnace at $1 \mathrm{~atm}$ for 1 hour and then passivated

d) The untreated samples were boiled in water and then passivated (O'Brien et al., 2002; Shabalovskaya, Rondelli, Anderegg, Simpson, \& Budko, 2003).

\section{RESULTS}

1) The porous NiTi sample with spherical shape pores is shown in Figure 1. The EDS spectrum in Figure 3 shows the complete removal of $\mathrm{NaCl}$ as the peaks of $\mathrm{Na}$ and $\mathrm{Cl}$ were absent. The average pore size was calculated by using a line intercept. By the Archimedes principle, the average porosity of the samples is $63.2 \%$ for $60 \mathrm{Vol} \% \mathrm{NaCl}$ and 53.6 for $50 \mathrm{Vol} \% \mathrm{NaCl}$ spacer. The porosity was within the range for implants (30-90\%) for improved bone ingrowth and integration.The figure reveals that the pore size and shape were replicated perfectly. The interconnections beneficial for tissue growth are indicated with arrows. Figure 2 shows the XRD pattern of the NiTi powder and Porous NiTi alloy. The pattern reveals the absence of Metallic Ni or Ti peaks for sintered NiTi. This ensures that the powders were sintered completely. The patterns also show the presence of small quantities of $\mathrm{Ti}_{2} \mathrm{Ni}$ and $\mathrm{Ni}_{3} \mathrm{Ti}$ along with austenite (B2) and martensitic NiTi (B19'). The XRD does not show $\mathrm{NaCl}$ peaks hence it confirms the removal of salt. However complete removal is not possible of the traces of $\mathrm{NaCl}$ but it is below the detection level. Table 1 shows the comparison of fabricated porous NiTi and different types of bones. Micro porosity can also be seen in the figure. Figure 4 shows the cyclic loading-unloading curves from compression testing. It can be seen that the strain up to $2 \%$ was almost completely recoverable in all samples, which is a replica of natural bones. The total recovery of strain at $8 \%$ is more than $75 \%$ in all samples. The super elasticity and shape memory properties of these porous alloys can be an asset in biomedical implants like hip replacement, knee joint replacement and dental implants. These alloys, when given a lover stress level, can recover without permanent deformation. This is similar to the natural behavior of bones in the presence of stress. The requirement of the longer life of implants and better osseointegration includes low modulus, high compression strength and high ductility which is observed in table 1 as well as in Table 2.

2) The corrosion parameters for the samples were calculated by conducting the cyclic polarization tests which are represented in Table 2 . The table shows the average corrosion parameters of five samples of Ni200. The samples which were etched, water boiled and passivated were found to have a better corrosion resistance in terms of $\mathrm{E}_{\mathrm{b}}-\mathrm{E}_{\mathrm{r}}$. The dry heated and passivated sample showed the least corrosion resistance. The etched, boiled and passivated sample had the etching of Nickel oxides from the surface which after boiling and passivating had a higher amount of titanium oxides on the surface of the sample which resulted in high corrosion resistance (Shabalovskaya et al., 2003). The least corrosion resistance of the later sample was due to the oxidation of NiTi alloy at higher temperatures, which led to the formation of Ni oxides on the surface (Li, Rong, \& Li, 2002; J. Wang et al., 2015). The other samples did not show any significant difference. Fig 5 shows the general corrosion of non treated sample. Fig 6 shows the comparison between $\mathrm{Eb}$ of untreated and etched, water boiled and passivated samples. 
Table 1. properties of Porous NiTi and different types of bones

\begin{tabular}{l|cccc}
\hline Sample & Density $\left(\mathrm{g} / \mathrm{cm}^{3}\right)$ & Ductility $(\%)$ & Modulus (GPa) & Compression Strength (MPa) \\
\hline 63.2 (spherical) & 2.17 & 14.72 & 1.89 & 107 \\
53.6 (spherical) & 2.05 & 14.05 & 1.96 & 103 \\
Cancellous bone & $0.1-1$ & $<7 \%$ & $0.01-3$ & $15-35$ \\
Cortical bone & $1.8-2$ & 1.9 & $4.4-28.8$ & $49-148$ \\
\hline
\end{tabular}

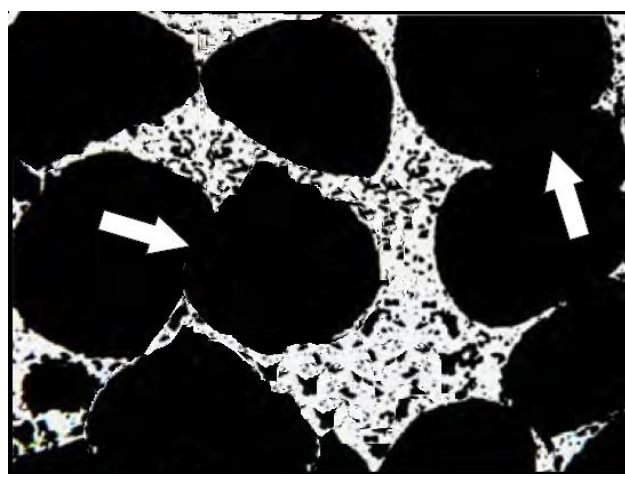

Fig 1. Porous NiTi sample with spherical pores

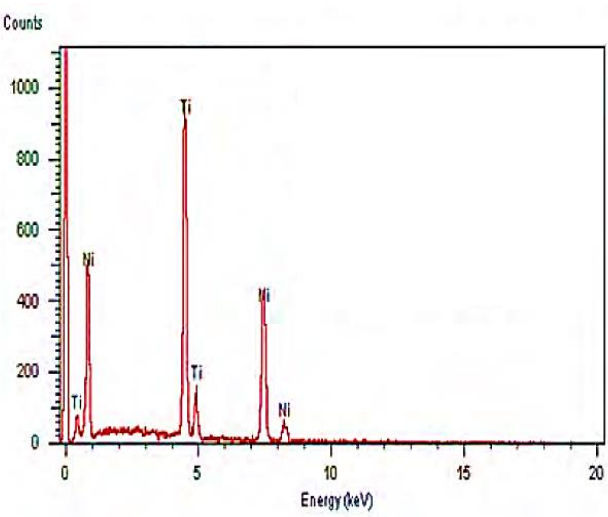

Fig 3. EDS graph of porous NiTi alloys

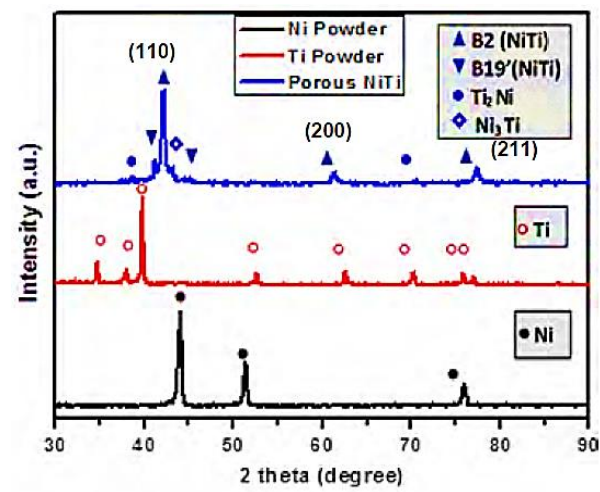

Fig 2. XRD pattern of the Ni and Ti powders and porous NiTi

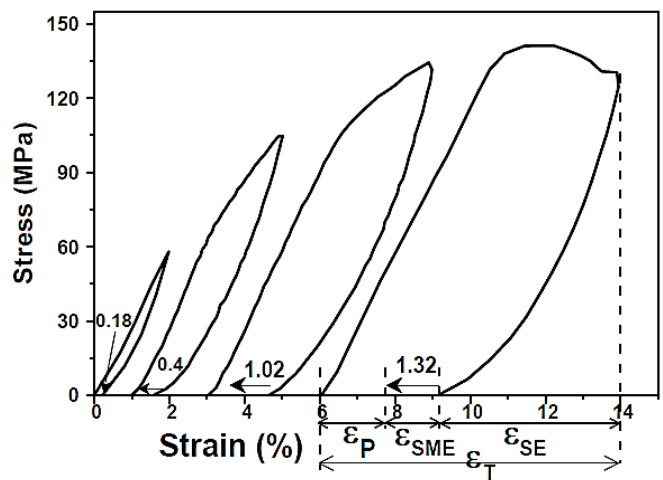

Fig 4. Cyclic loading-unloading curves at $8 \%$ strain of porous NiTi

Table 2. Corrosion Parameters for the samples

\begin{tabular}{l|ccccc}
\hline $\begin{array}{l}\text { Corrosion } \\
\text { parameter }\end{array}$ & $\begin{array}{c}\text { Untreated } \\
\text { sample }\end{array}$ & $\begin{array}{c}\text { Etched, boiled } \\
\text { and passivated }\end{array}$ & $\begin{array}{c}\text { Dry heated } \\
\text { and passivated }\end{array}$ & $\begin{array}{c}\text { Water Boiled } \\
\text { and passivated }\end{array}$ & Etched \\
\hline $\mathrm{E}_{\mathrm{b}}, \mathrm{V}$ & 1.067 & 1.1102 & 1.0346 & 1.0334 & 0.9621 \\
$\mathrm{E}_{\mathrm{r}}, \mathrm{V}$ & -0.2127 & -0.2213 & -0.1121 & -0.1864 & -0.3982 \\
$\mathrm{E}_{\mathrm{p}}, \mathrm{V}$ & 1.0336 & 1.0132 & 0.8321 & 0.8300 & 0.8625 \\
$\mathrm{E}_{\mathrm{b}}-\mathrm{E}_{\mathrm{r}}, \mathrm{V}$ & 1.2797 & 1.3315 & 1.1467 & 1.2198 & 1.3603 \\
\hline
\end{tabular}

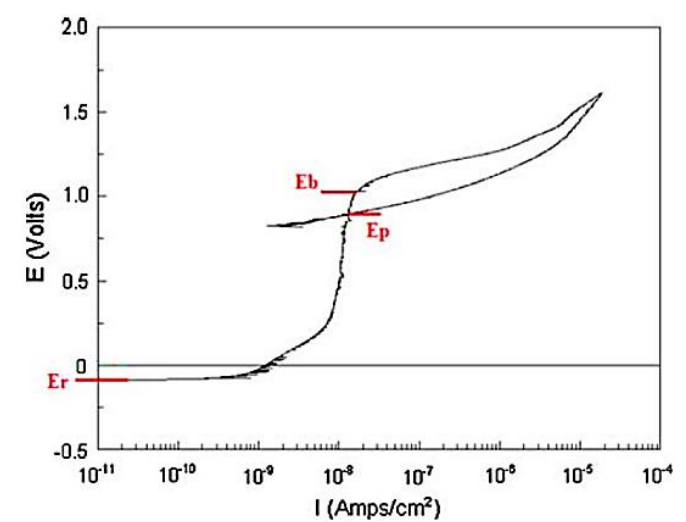

Fig 5. Cyclic polarization curve of etched sample

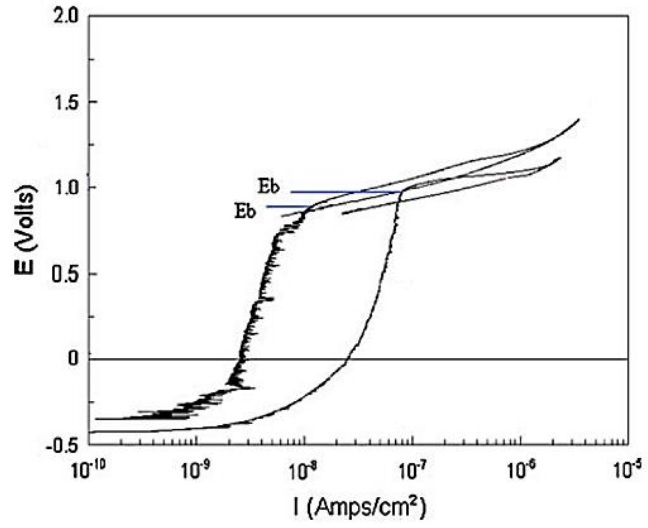

Fig 6. Eb values for (1) untreated and (2) etched, water boiled and passivated samples 


\section{CONCLUSION}

The fabrication of Porous NiTi alloy with spherical pore morphology and size was accomplished for biomedical implant application. The shape and size of the samples was a replica of spacer powder. A total recovery of more than $75 \%$ at $8 \%$ absolute strain was achieved. The compression properties prove to be suitable for biomedical implants. To understand the local corrosion of the surface treated Ni200 samples, in vitro corrosion tests (ASTM F 2129-08) in PBS solution were conducted. As NiTi alloys oxidation at high temperatures leads to the formation of nickel oxides on the surface which is more prone to corrosion. This is verified in the samples which were dry heated and passivated. The

\section{REFERENCES}

Abidi, I. H., Khalid, F. A., Farooq, M. U., Hussain, M. A., \& Maqbool, A. (2015). Tailoring the pore morphology of porous nitinol with suitable mechanical properties for biomedical applications. Materials Letters, 154, 17-20.

Aihara, H., Zider, J., Fanton, G., \& Duerig, T. (2019). Combustion synthesis porous nitinol for biomedical applications. International journal of biomaterials, 2019.

Geetha, M., Singh, A. K., Asokamani, R., \& Gogia, A. K. (2009). Ti based biomaterials, the ultimate choice for orthopaedic implants-a review. Progress in materials science, 54(3), 397-425.

Huang, W., Ding, Z., Wang, C., Wei, J., Zhao, Y., \& Purnawali, H. (2010). Shape memory materials. Materials today, 13(7-8), 54-61.

Kapoor, D. (2017). Nitinol for medical applications: A brief introduction to the properties and processing of nickel titanium shape memory alloys and their use in stents. Johnson Matthey Technology Review, 61(1), 66-76.

Li, Y.-H., Rong, L.-J., \& Li, Y.-Y. (2002). Compressive property of porous NiTi alloy synthesized by combustion synthesis. Journal of alloys and compounds, 345(1-2), 271274.

O’Brien, B., Carroll, W., \& Kelly, M. (2002). Passivation of nitinol wire for vascular implants-a demonstration of the benefits. Biomaterials, 23(8), 1739-1748. samples which were etched, water boiled and passivated showed a high proportion of Ti oxide on the surface which led to high corrosion resistance. By this it can be determined that such NiTi alloys can be distinctively used for interbody fusions and can be designed into various very useful components for replacements in biomedical implants.

\section{ACKNOWLEDGEMENTS}

The author thanks Dr. I.B.Patel for his guidance and his encouragement and Dr. K.C. Poria, Head, Department of Physics, Veer Narmad South Gujarat University, Surat for providing laboratory facilities.

Pelton, A. R., Dicello, J., \& Miyazaki, S. (2000). Optimisation of processing and properties of medical grade Nitinol wire. Minimally Invasive Therapy \& Allied Technologies, 9(2), 107-118.

Shabalovskaya, S., Rondelli, G., Anderegg, J., Simpson, B., \& Budko, S. (2003). Effect of chemical etching and aging in boiling water on the corrosion resistance of nitinol wires with black oxide resulting from manufacturing process. Journal of Biomedical Materials Research Part B: Applied Biomaterials: An Official Journal of The Society for Biomaterials, The Japanese Society for Biomaterials, and The Australian Society for Biomaterials and the Korean Society for Biomaterials, 66(1), 331-340.

Thierry, B., Tabrizian, M., Trepanier, C., Savadogo, O., \& Yahia, L. H. (2000). Effect of surface treatment and sterilization processes on the corrosion behavior of NiTi shape memory alloy. Journal of biomedical materials research, 51(4), 685-693.

Wang, J., Zhou, B., Liu, X. S., Fields, A. J., Sanyal, A., Shi, X., Guo, X. E. (2015). Trabecular plates and rods determine elastic modulus and yield strength of human trabecular bone. Bone, 72, 71-80.

Wang, X., Xu, S., Zhou, S., Xu, W., Leary, M., Choong, P., Xie, Y. M. (2016). Topological design and additive manufacturing of porous metals for bone scaffolds and orthopaedic implants: A review. Biomaterials, 83, 127-141. 